\title{
Characterisation of the rapid release of activin A following acute lipopolysaccharide challenge in the ewe
}

\author{
K L Jones, D M de Kretser, I J Clarke ${ }^{1}$, J-P Y Scheerlinck ${ }^{2}$ and \\ D J Phillips \\ Monash Institute of Reproduction and Development, Monash University, Clayton, Victoria, Australia \\ ${ }^{1}$ Prince Henry's Institute of Medical Research, Clayton, Victoria, Australia \\ ${ }^{2}$ Centre for Animal Biotechnology, The University of Melbourne, Victoria, Australia \\ (Requests for offprints should be addressed to D J Phillips, Centre for Molecular Reproduction and Endocrinology, Monash Institute of Reproduction and \\ Development, 27-31 Wright Street, Clayton 3168, Victoria, Australia; Email: david.phillips@med.monash.edu.au)
}

\begin{abstract}
A series of experiments were conducted in adult ewes to delineate the release profile of activin A and its relationship to other cytokines following an i.v. injection of the bacterial cell wall component, lipopolysaccharide (LPS). Following this challenge, plasma activin A increased rapidly and appeared to be released in a biphasic manner, slightly preceding the release of tumour necrosis factor- $\alpha$ (TNF $\alpha$ ) and before elevation of interleukin (IL)-6 and follistatin levels. The concentration of activin A was correlated with body temperature during the response to LPS. A second experiment compared cytokine concentrations in matched blood and cerebrospinal fluid (CSF) samples. This revealed that activin A was not released centrally in the CSF following a peripheral LPS injection, nor was TNF $\alpha$ or the activin binding protein, follistatin, but IL-6 showed a robust elevation. In a third experiment, the stimulus for activin A release was examined by
\end{abstract}

blocking prostaglandin synthesis. Flurbiprofen, a prostaglandin synthesis inhibitor, effectively attenuated the fever response to LPS and partly inhibited cortisol release, but the cytokine profiles were unaffected. Finally, the bioactivity of TNF $\alpha$ and/or IL-1 was blocked using soluble receptor antagonists. These treatments did not affect the initial release of activin A, but blockade of TNF $\alpha$ depressed the second activin peak. These studies define more rigorously the release of activin A into the circulation following acute inflammatory challenge. The response is rapid and probably biphasic, independent of prostaglandinmediated pathways and does not depend upon stimulation by TNF $\alpha$ or IL-1. The data suggest that activin A release is an early event in the inflammatory cascade following the interaction of LPS with its cellular receptor.

Journal of Endocrinology (2004) 182, 69-80

\section{Introduction}

Inflammation is a multifaceted process essential for the resolution of trauma or infection, where tissue injury is repaired and infectious agents are eliminated. This occurs at cellular, tissue and systemic levels, mediated by the release of a wide range of cytokines. A key component of the inflammatory response is the ordered and structured release of pro-inflammatory cytokines such as tumour necrosis factor- $\alpha$ (TNF $\alpha$ ), interleukin (IL)-1 $\beta$ and IL-6, classic early release cytokines which stimulate prostaglandin production both peripherally and centrally (Kluger 1991, Ushikubi et al. 1998, Ek et al. 2001). The elevation in body temperature (fever) is induced and coordinated by the release of these cytokines which act as endogenous pyrogens. The fever response represents an adaptive mechanism to facilitate host resistance and to inhibit the spread of pathogens (Kluger 1991).
As well as these classic cytokines, activin A levels are also elevated in response to inflammation. This dimeric protein is a member of the transforming growth factor- $\beta$ (TGF $\beta$ ) superfamily, yet is structurally and functionally distinct from TGF $\beta$. Activin A was originally isolated as a protein involved in reproduction, but is now known to have widespread actions in many tissues at various phases of life (Phillips 2003). Activin A is a dimer of two inhibin $\beta_{\mathrm{A}}$ subunits with inhibin, another TGF $\beta$ superfamily member, formed by one $\alpha$ and one $\beta$ subunit (Phillips 2001). Activin B is formed from two inhibin $\beta_{\mathrm{B}}$ subunits, although immunomodulatory activities for activin $\mathrm{B}$ together with inhibin have not been demonstrated.

We have previously shown that activin A is released rapidly into the circulation following an injection of the inflammatory mediator, lipopolysaccharide (LPS) (Jones et al. 2000). LPS functions through a specific Toll-like 
receptor (TLR), TLR4, and activates an inflammatory cascade of events through the adapter protein, nuclear factor- $\mathrm{KB}(\mathrm{NF}-\kappa \mathrm{B})$ (Hanada \& Yoshimura 2002). In vitro studies have revealed that activin $\mathrm{A}$ can act in either a pro- or anti-inflammatory manner in a number of different cell types and cell lines. Activin A is capable of antagonising IL-6-stimulated production of acute phase proteins and IL-1 $\beta$ bioactivity in monocytic cell lines (Brosh et al. 1995, Ohguchi et al. 1998), but is also capable of stimulating the production of inflammatory cytokines, prostanoids and nitric oxide synthase in activated macrophages (Nüsing \& Barsig 1999). These data indicate that activin A release during inflammation, through its interaction points with other cytokines, may be important in modulating inflammatory responses. Importantly, activin has been more recently implicated in a number of inflammatory conditions, such as in wound healing (Hübner et al. 1996). Follistatin is a binding protein for activin which can neutralise the majority of its actions, and is also upregulated in various inflammatory models (Phillips et al. 2001). With acute inflammation, such as that induced by LPS, the release of follistatin occurs later than that of activin A, suggesting that follistatin production may be a downstream consequence of activin A activation. In the clinical setting, activin $\mathrm{A}$ and follistatin are elevated in the serum of patients with septicaemia (Michel et al. 2003a), and follistatin is higher in the cerebrospinal fluid (CSF) of patients with meningitis (Michel et al. 2000). Activin A levels are also elevated in the synovial fluid of rheumatoid arthritis patients ( $\mathrm{Yu} \&$ Dolter 1997), and activin A expression is co-localised and correlates with IL- $1 \beta$ expression levels in inflammatory bowel disease (Hübner et al. 1997).

The precise mechanisms and stimuli for activin A and follistatin release during inflammation are not well understood. Our earlier description of the response following LPS challenge (Jones et al. 2000) was not focused particularly on the rapid release of activin A. Therefore, the current aim was to define more rigorously the early acute release of activin $\mathrm{A}$ and to determine whether it was related to and affected by other cytokines released early in the inflammatory response. A complementary aim was to establish if the rapid release of activin A was affected by blocking critical components of the inflammatory cascade. Thus, prostaglandin release was blocked with the prostaglandin synthase inhibitor, flurbiprofen, and the bioactivity of TNF $\alpha$ and IL-1 was blocked using specific receptor antagonists. As key cytokines, such as IL-6, are released into both the circulation and the CSF following exposure to LPS, activin A and follistatin concentrations were measured in both compartments. All the studies were performed in a well-characterised model of i.v. injection of LPS in adult conscious ewes, which mount a similar inflammatory response to that of human subjects.

\section{Materials and Methods}

\section{Animals and general experimental details}

All experiments were conducted in accordance with the National Health and Medical Research Council of Australia (NHMRC) Code of Practice for the Care of Animals for Scientific Purposes (1997) and were approved by the Victorian Institute of Animal Sciences Animal Ethics Committee.

For Experiments 1, 3 and 4, adult Corriedale ewes (median weight $62.5 \mathrm{~kg}$, range $44-74.5 \mathrm{~kg}$ ) were randomly allocated to treatment groups and housed indoors in individual pens with access to a maintenance ration of lucerne chaff and freely available tap water. For Experiment 2, adult Corriedale ewes were fitted with guide tubes in the third cerebral ventricle at least 1 month before the current studies, as previously described (Barker-Gibb et al. 1995). The day before experiments, indwelling catheters (Dwellcath; Tuta Laboratories, Lane Cove, Australia) were inserted into the external jugular vein under local anaesthesia. A bleeding line (Manometer tubing; Tuta) with a three-way tap was attached to the catheter and run to the back of the pen to allow blood samples to be collected with minimal disturbance to the animal. Throughout the studies, patency of the catheters was maintained with $0.9 \%$ saline solution containing $37 \mathrm{mM}$ dipotassium EDTA (BDH Laboratory Supplies, Poole, Dorset, UK), which does not affect circulating concentrations of activin A or follistatin. Blood samples $(5 \mathrm{ml})$ were centrifuged $\left(250 \mathrm{~g}\right.$ at $\left.4{ }^{\circ} \mathrm{C}\right)$ in tubes containing EDTA $(50 \mu \mathrm{l} 740 \mathrm{mM}$ EDTA solution per tube). Plasma was stored at $-20{ }^{\circ} \mathrm{C}$ until assayed. In Experiment 2, CSF samples $(2 \mathrm{ml})$ were collected from the guide tube accessing the third ventricle and were stored at $-20{ }^{\circ} \mathrm{C}$ until assayed. Between CSF sampling, artificial, sterile CSF $\left(150 \mathrm{mM} \mathrm{NaCl}, 1.2 \mathrm{mM} \mathrm{CaCl} 2,1 \mathrm{mM} \mathrm{MgCl}_{2}\right.$, $2.8 \mathrm{mM} \mathrm{KCl}$ ) was infused into the third ventricle using a portable infusion pump (Graseby Medical Ltd, Gold Coast, Australia) at a rate of $50 \mu \mathrm{l} / \mathrm{h}$. Body temperature in all studies was measured using a digital rectal thermometer.

LPS (E. coli serotype 0127:B8; Sigma, St Louis, MO, USA) was administered as an i.v. bolus injection of $50 \mu \mathrm{g}$ in $5 \mathrm{ml}$ isotonic, non-pyrogenic saline solution. This dose of LPS has been used routinely in ewes to stimulate a predictable but moderate acute inflammatory response (Jones et al. 2000). The prostaglandin synthesis inhibitor, flurbiprofen (Sigma), was dissolved in 95\% ethanol at a concentration of $200 \mathrm{mg} / \mathrm{ml}$ and injected i.v. at a dose of $2 \mathrm{mg} / \mathrm{kg}$ in $5 \mathrm{ml}$ non-pyrogenic saline. This dose has been used previously in sheep to block prostaglandin release (Harris et al. 2000). Animals in control groups received, at equivalent volumes or doses, non-pyrogenic saline solution instead of LPS and/or 95\% ethanol instead of flurbiprofen. Pegylated-recombinant met-human-soluble 
TNF $\alpha$ receptor (sTNF $\alpha$ R) (Amgen, Thousand Oaks, CA, USA) was injected at a dose of $1 \mathrm{mg} /$ ewe in $5 \mathrm{ml}$ non-pyrogenic saline. Recombinant met-human-IL-1 receptor antagonist (IL-1RA) (Amgen) was injected as a bolus of $5 \mathrm{mg}$ /ewe followed by an infusion of $3 \mathrm{mg} / \mathrm{h}$ per ewe in non-pyrogenic saline over the next $4 \mathrm{~h}$. The doses of these antagonists have been used previously to block the effect of LPS on TNF $\alpha$-induced mortality in baboons, IL-6 synthesis in human peripheral blood cells and growth hormone secretion in sheep (Granowitz et al. 1992, Daniel et al. 2001, Rosenberg et al. 2001).

\section{Experiment 1: characterisation of the early release of activin $A$ following LPS treatment}

The aim of this experiment was to define the pattern of acute release of activin $\mathrm{A}$ and its temporal relationship to the release of pro-inflammatory cytokines. Furthermore, as the fever response to LPS stimulation is classically biphasic (Kluger 1991), it was ascertained whether the activin A and follistatin responses followed this pattern. Ewes were treated with $50 \mu \mathrm{g}$ LPS $(n=5)$ or vehicle $(n=3)$ and matched blood samples and temperature readings were collected before injection, at $10 \mathrm{~min}$ intervals for the first hour after injection, then every $15 \mathrm{~min}$ until $8 \mathrm{~h}$ after injection. Two additional samples were collected at 24 and $32 \mathrm{~h}$ after LPS injection. Plasma samples were assayed for activin A, follistatin, TNF $\alpha$ and IL-6.

\section{Experiment 2: comparison of peripheral vs central response to LPS}

This experiment determined whether activin A was released within the central nervous system (CNS) following LPS injection, as has been documented for other cytokines such as IL-6 (Klir et al. 1993). Animals with third ventricular guide tubes were given an i.v. injection of $50 \mu \mathrm{g}$ LPS $(n=6)$ or vehicle $(n=4)$. Blood samples were collected and temperatures recorded as in Experiment 1. CSF samples were collected at 20 min intervals and, where appropriate, in synchrony with blood sampling. Plasma and CSF were assayed for activin A, follistatin, TNF $\alpha$ and IL-6. To determine whether activin A either had a central effect on cytokine release or was pyrogenic like other key cytokines such as IL-6 (Kluger 1991), a small pilot study was conducted in four ewes prepared for third ventricular sampling. A larger study was not undertaken because of the limited availability of highly purified activin A. The animals received either $1(n=2)$ or $5 \mu \mathrm{g}(n=2)$ of human recombinant activin A (National Hormone and Pituitary Program (NHPP, Torrance, CA, USA)), in $0.1 \mathrm{ml}$ non-pyrogenic saline infused over $2 \mathrm{~min}$ into the third ventricle of the brain. Blood and CSF were assayed for activin A, follistatin, TNF $\alpha$ and IL-6.
Experiment 3: blockade of the LPS-stimulated fever response with flurbiprofen

This experiment investigated whether activin A release was dependent on a prostaglandin-mediated mechanism. Further, the relationship between fever and activin A release was investigated to identify whether there was a direct relationship between fever and activin A release. Flurbiprofen, a prostaglandin synthase inhibitor, was used to ablate the LPS-induced fever response. Previous studies have also demonstrated that several LPSmediated responses such as cortisol (Massart-Leen et al. 1992), oxytocin, growth hormone (Massart-Leen \& Vandeputte-Van Messom 1991) and gonadotrophinreleasing hormone $(\mathrm{GnRH})$ release (Harris et al. 2000) are fully or partially prostaglandin-dependent. Four groups of animals ( $n=5$ /group) received either vehicle only (ethanol and saline), flurbiprofen alone, LPS alone or flurbiprofen plus LPS. Either flurbiprofen or the ethanol vehicle was administered i.v. $30 \mathrm{~min}$ before LPS injection. Blood samples were collected and matched temperature readings were made using the same protocol as in Experiment 1 and plasma was assayed for activin A, follistatin, TNF $\alpha$ and IL-6.

\section{Experiment 4: blockade of TNFa and IL-1 effects following} LPS stimulation

The aim of this experiment was to study whether activin A release was affected by blocking the action of the pro-inflammatory cytokines, TNF $\alpha$ and IL-1. Four groups of animals ( $n=5$ per group) received i.v. injections of either LPS $(50 \mu \mathrm{g})$ or vehicle (saline), or sTNF $\alpha \mathrm{R}$ ( $1 \mathrm{mg} /$ ewe), or IL-1RA ( $5 \mathrm{mg}$ /ewe and $1 \mathrm{mg} / \mathrm{h}$ per ewe) or sTNF $\alpha$ R plus IL-1RA. Previous studies have demonstrated that administration of these cytokine antagonists during endotoxaemia can reduce cytokine production, mortality rates and growth hormone release (Granowitz et al. 1992, Daniel et al. 2001, Rosenberg et al. 2001). The doses of the antagonists were based on the studies of Daniel et al. (2001). Blood samples were collected and matched temperature readings were made using the same protocol as in Experiment 1 and plasma was assayed for activin A, follistatin, TNF $\alpha$ and IL-6.

Assays

Activin A was measured in an ELISA format as previously described (Knight et al. 1996). This assay measures both free and follistatin-bound activin and has been extensively validated for both sheep plasma and CSF. The standard was human recombinant activin A (NHPP). The mean sensitivity was $0 \cdot 01 \mathrm{ng} / \mathrm{ml}$, and the mean intra- and inter-assay coefficient of variation $(\mathrm{CV})$ values were 3.9 and $5 \cdot 1 \%$ respectively.

Follistatin was measured by an RIA as previously described (Klein et al. 1991), which measures both free 
and bound forms. The assay employs purified heterologous bovine follistatin as standard and uses iodinated bovine follistatin as tracer, as previously described (Robertson et al. 1987). The assay sensitivity was $2 \cdot 7 \mathrm{ng} / \mathrm{ml}$, the mean $\mathrm{ED}_{50}$ was $13.3 \mathrm{ng} / \mathrm{ml}$ and the intra- and inter-assay CV values were $6 \cdot 4$ and $10 \cdot 2 \%$ respectively.

TNF $\alpha$ was measured by an ELISA specific for the ovine form as previously described (Jones et al. 2000) with minor modifications. The standard employed was ovine recombinant TNFa (Centre for Animal Biotechnology (CAB), University of Melbourne, Australia). The sensitivity of the assay was $0.5 \mathrm{ng} / \mathrm{ml}$, and the intra- and inter-assay CV values were both $<10 \%$. IL-6 was detected by ELISA as previously described (Jones et al. 2000), using antibodies specific to ovine IL-6 (Epitope Technologies, Melbourne, Australia). The standard was ovine recombinant IL-6 from $\mathrm{CAB}$. The sensitivity of the assay was $0 \cdot 2 \mathrm{ng} / \mathrm{ml}$ and the intra- and inter-assay CV values were $<10$ and $12 \%$ respectively.

Cortisol was measured using an RIA as previously described (Bocking et al. 1986). This assay employs sheep antiserum raised against human cortisol. The standard employed was purified cortisol (Sigma) and the tracer was $\left[{ }^{3} \mathrm{H}\right]$ cortisol (Amersham). The sensitivity of the assay was $0.5 \mathrm{ng} / \mathrm{ml}$ and the intra- and inter-assay $\mathrm{CV}$ values were both $<15 \%$.

For the measurement of cytokine levels in plasma samples assayed by ELISA the appropriate standard preparation was diluted in PBS $(0 \cdot 01 \mathrm{M})$ with 5\% BSA. Because of the low protein content of CSF, the standard diluent used in CSF assays was 0.05\% BSA in PBS. A 20\% solution of BSA in PBS $(25 \mu \mathrm{l})$ was added to the wells before the addition of CSF samples as this was found to enhance the reproducibility of the assay.

\section{Data analysis}

All plasma and temperature data were log transformed before statistical analysis. Repeated-measures ANOVA was used to identify significant effects of treatment. Where appropriate, cytokine and temperature responses were estimated using an area under the curve (AUC) function (GraphPad version 2.01; GraphPad Software Inc., San Diego, CA, USA). The AUC was calculated for the data presented in Experiment 4 and expressed as a percentage as compared with the LPS alone-treated group. The two peaks in the temperature and activin A profiles were assessed independently (Phase I and Phase II), defined as 0-2 h (Phase I) and 2-24 h (Phase II). Follistatin, TNFa and IL-6 responses were assessed as monophasic profiles. When significant treatment effects were identified, post-hoc multiple comparisons were carried out using Dunnett's test. To analyse differences between treatment groups a paired $t$-test was used. Correlation analyses in Experiment 1 were performed over the entire activin profile using the Spearman test.

\section{Results}

Experiment 1: characterisation of the early release of activin $A$ following LPS treatment

Fever developed within $1 \mathrm{~h}$ of LPS injection and exhibited a classic biphasic pattern of response, initially peaking at $1.3 \mathrm{~h}$ and again at $3.5 \mathrm{~h}(P<0.01)$. The first significant $(P<0 \cdot 01)$ increase in temperature occurred $50 \mathrm{~min}$ after LPS (Fig. 1A). The release of activin A following LPS injection was rapid, with the first detectable increase in concentration above baseline levels occurring at $50 \mathrm{~min}$ $(P<0 \cdot 01)$, consistent with the first significant increase in body temperature. Like the fever response, the profile of activin A was biphasic, although the clear distinction of two peaks varied from animal to animal, with the mean peak times being at $\sim 1 \mathrm{~h}$ and $\sim 3.75 \mathrm{~h}$ (Fig. 1B). Correlation analyses showed that for all five ewes treated with LPS, there was a significant $(P<0 \cdot 01)$ association between temperature and activin A concentrations over the entire profile; the median Spearman correlation coefficient, $r_{s}$, was 0.68 (range $0.54-0.77$ ). The correlation for one of these animals from Experiment 1 is represented in Fig. 1F.

The elevation in plasma levels $(P<0 \cdot 01)$ of activin A slightly preceded that of TNF $\alpha$ (Fig. 1C) (activin: $50 \mathrm{~min}$ vs TNF $\alpha$ : $60 \mathrm{~min}$ ). The TNF $\alpha$ response was in the form of a monophasic peak within $2 \mathrm{~h}$, although concentrations remained elevated for up to $5 \mathrm{~h}$. In contrast, IL- 6 was released later than either activin A or TNF $\alpha$, with the first significant $(P<0 \cdot 01)$ elevation in plasma levels seen at $3.75 \mathrm{~h}$, remaining elevated until $8 \mathrm{~h}$ after LPS (Fig. 1D). Follistatin release was delayed and prolonged compared with activin A; plasma levels increased slowly from $3 \mathrm{~h}$, peaked at $8 \mathrm{~h}$ and remained significantly elevated for $24 \mathrm{~h}$ $(P<0 \cdot 01)$ (Fig. 1E).

\section{Experiment 2: comparison of the peripheral vs central response} to LPS

Plasma profiles following i.v. LPS were generally consistent with those described for Experiment 1. Although the second peak of activin A release was diminished and an extended release of TNF $\alpha$ was apparent, the profiles of IL-6 and follistatin were similar (Fig. 2A-D). In contrast, while TNF $\alpha$ levels were uniformly below assay sensitivity, activin A and follistatin were detectable in CSF, with no apparent change following the LPS challenge (Fig. 2A-C). CSF levels of IL-6, however, were elevated in response to LPS treatment, with kinetics similar to those seen in plasma (Fig. 2D). It was notable that plasma IL-6 concentrations were around 3-fold higher than in matched CSF samples. Control animals, injected with non-pyrogenic saline, did not display any significant change in plasma or CSF levels of cytokines or in rectal temperature (data not shown). 
A

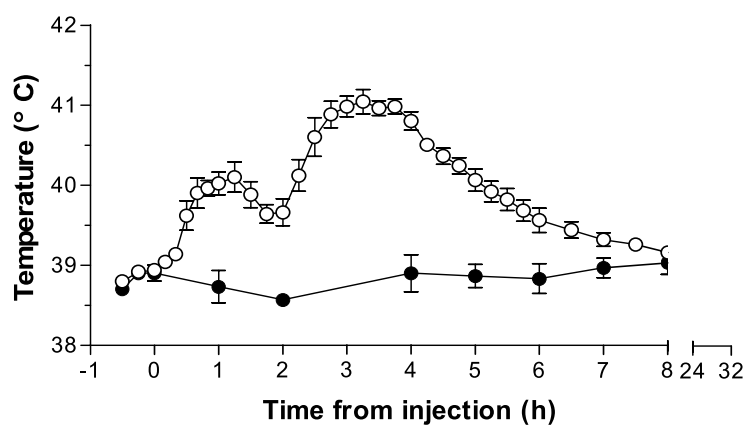

B

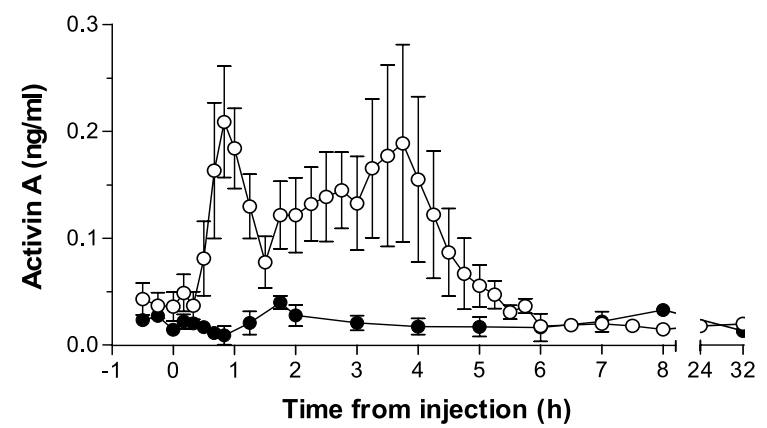

C

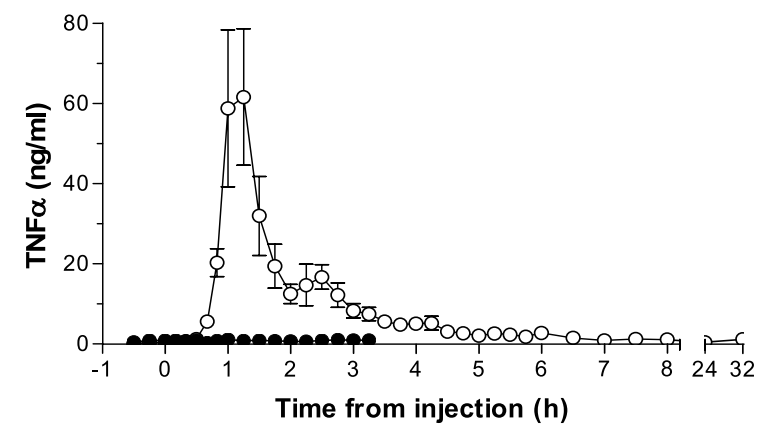

D

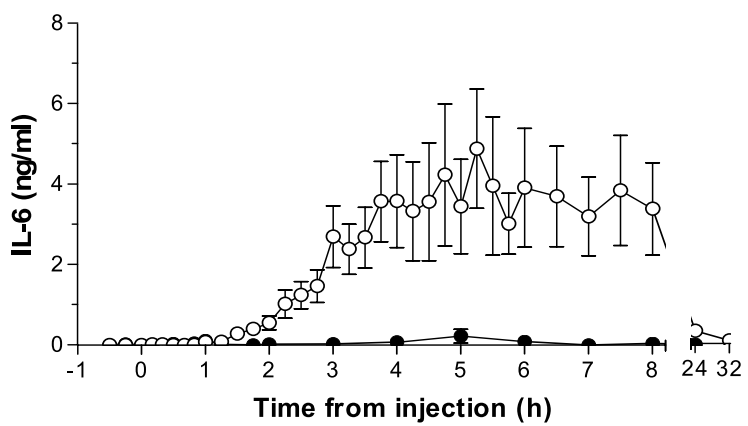

$\mathbf{E}$

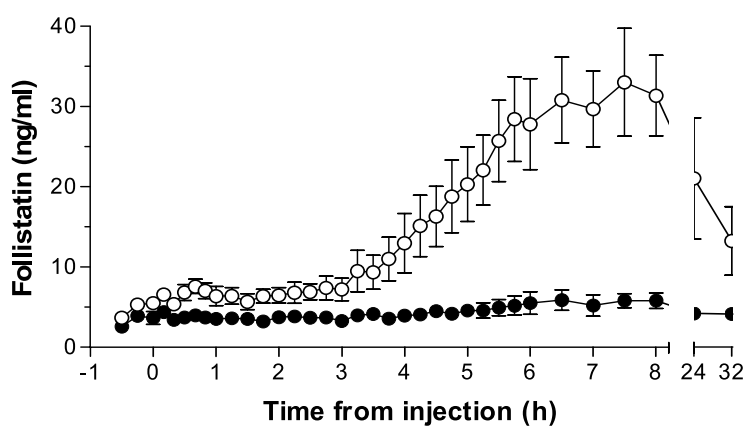

$\mathbf{F}$

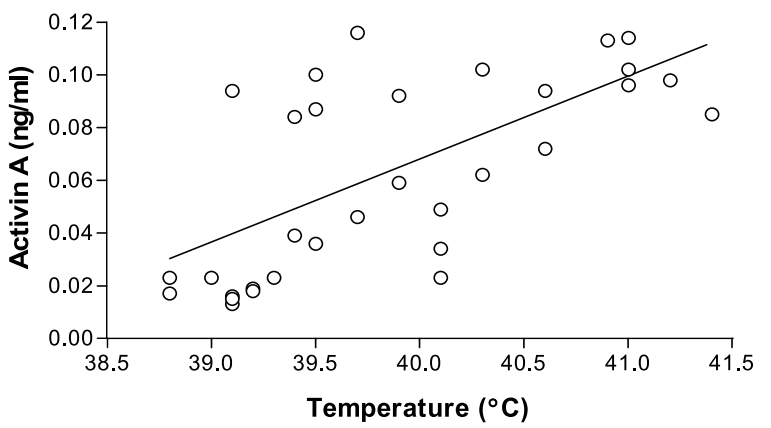

Figure 1 The response of adult ewes to an injection of LPS $(50 \mu \mathrm{g})(\mathrm{O}), n=5$ or non-pyrogenic saline $(\mathbf{O}), n=3$, in terms of $(\mathrm{A})$ body temperature, (B) activin A, (C) TNFa, (D) IL-6 and (E) follistatin. Panel (F) represents the association between temperature and activin A concentrations in an individual ewe. Values in (A-E) are means \pm S.E.M.

A pilot study showed that central administration of activin A elevated the concentrations in CSF (data not shown). Peak levels achieved in CSF $(\sim 3.5 \mathrm{ng} / \mathrm{ml})$ were about 30 times greater than those measured in CSF from untreated animals. However, following the administration of activin A, no changes were noted in CSF or plasma concentrations of TNFa, IL-6 or follistatin, or in the rectal temperature profiles (data not shown). 
A

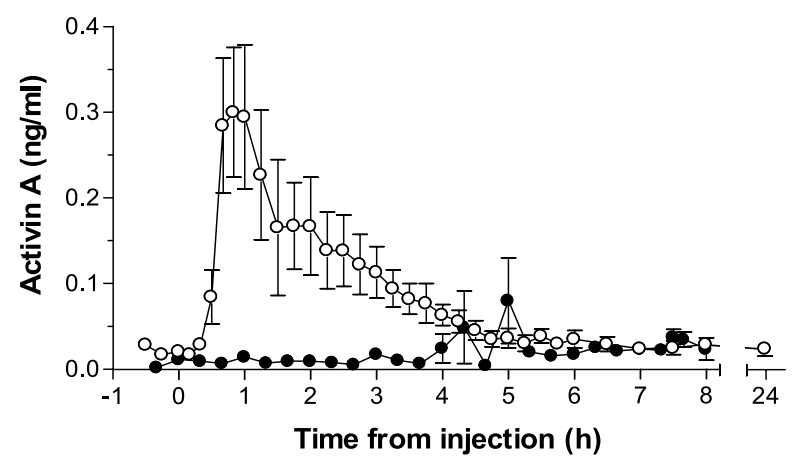

B

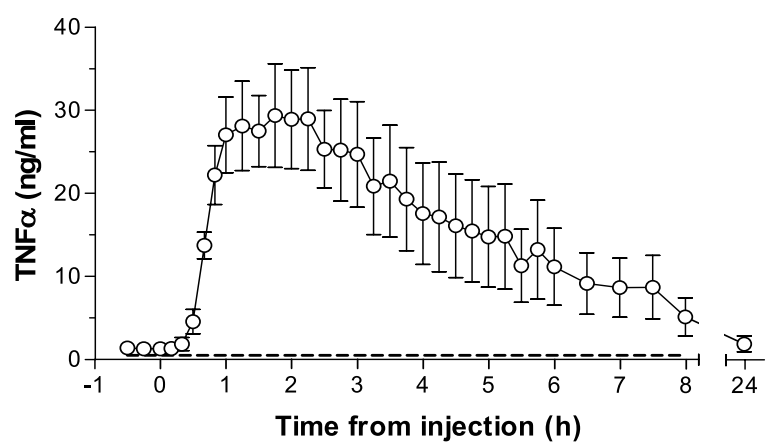

C

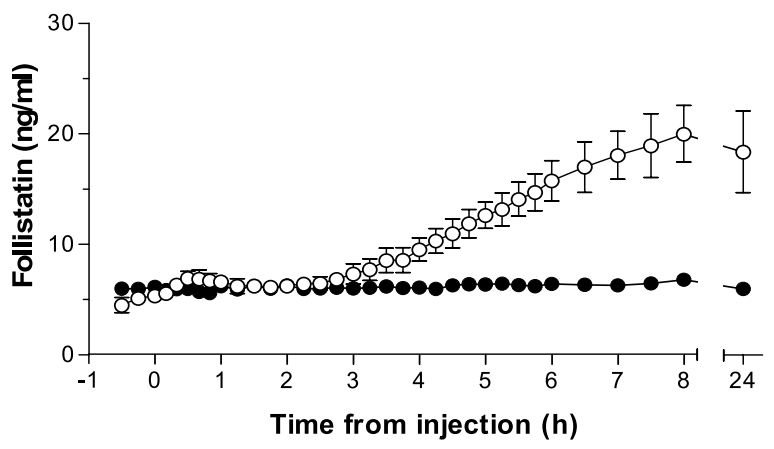

D

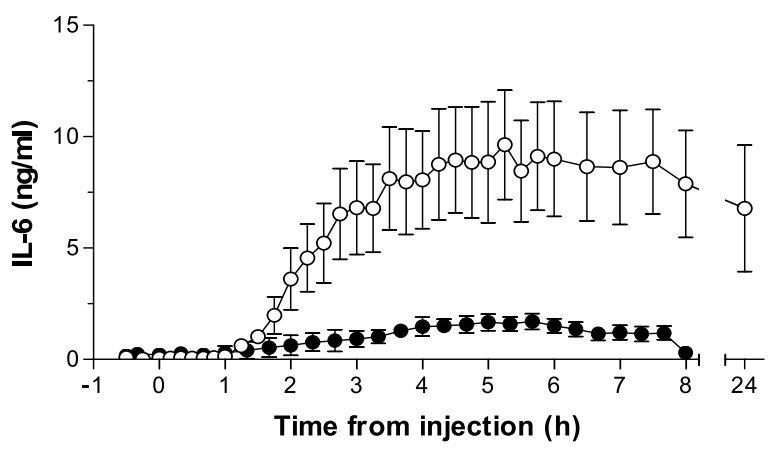

Experiment 3: blockade of the LPS-stimulated fever response with flurbiprofen

Injection of flurbiprofen at $2 \mathrm{mg} / \mathrm{kg} 30 \mathrm{~min}$ before LPS almost prevented the first peak of the traditional biphasic fever response and completely ablated the second peak (Fig. 3A). An injection of flurbiprofen alone had no significant effect on rectal temperature except for a minor and transient increase in temperature in the first $30 \mathrm{~min}$ (data not shown). This effect appeared to be non-specific as small increases in body temperature were also detected in the control group, perhaps reflecting the increased activity of the animals with the commencement of blood sampling. Despite blocking the fever response in LPStreated ewes, flurbiprofen in conjunction with LPS did not perturb the release profiles for activin A, TNF $\alpha$, IL- 6 or follistatin (Fig. 3B-E). Nevertheless, cortisol concentrations in these animals revealed that treatment with flurbiprofen significantly $(P<0 \cdot 01)$ inhibited the release of cortisol between $40 \mathrm{~min}$ and $2 \mathrm{~h}$, as compared with the LPS-treated group (Fig. 3F). Furthermore, flurbiprofen alone had no effect on plasma cytokine concentrations (data not shown).

\section{Experiment 4: blockade of TNFa and IL-1 effects following} LPS stimulation

Following an injection of LPS in animals administered sTNF $\alpha$ R and/or IL-1RA, there was an increase in the peak temperature levels in the first fever response and a prolonged second fever peak, but no significant $(P>0 \cdot 05)$ increase in the AUC was apparent (Fig. 4A and Fig. 5A). The release of activin $A$ in response to LPS challenge was once again biphasic as observed in Experiment 1 (Fig. $4 \mathrm{~B})$. The administration of either antagonist or both together had no effect on the initial release of activin A (Fig. 4B and Fig. 5B). However, all combinations of administration of the antagonists had a similar level of suppression on the second release of activin A, although only sTNF $\alpha$ R significantly suppressed the second peak of activin A in plasma $(P<0.03$, Fig. 5B). The release of follistatin was suppressed most by the blockade of TNF $\alpha$ $(P=0.054$, Fig. 4C and Fig. 5C), which also caused the greatest suppression of activin A levels in plasma. Release of TNF $\alpha$ was not significantly altered following the administration of either antagonist (Fig. 4D and Fig. 5D). However, the release of IL-6 was suppressed by $35 \%$ with the blockade of TNFa (Fig. 5E). Interestingly,

Figure 2 Changes in plasma $(O)$ and $\operatorname{CSF}(-$ ) concentrations of (A) activin A, (B) TNF $\alpha,(C)$ follistatin and (D) IL-6, following i.v. injection of $50 \mu \mathrm{g}$ LPS in adult ewes $(n=6)$. Values are means \pm S.E.M. Concentrations of TNF $\alpha$ in CSF were below the minimum detectable level of the assay, which is represented as a dashed line in the appropriate panel. 
A

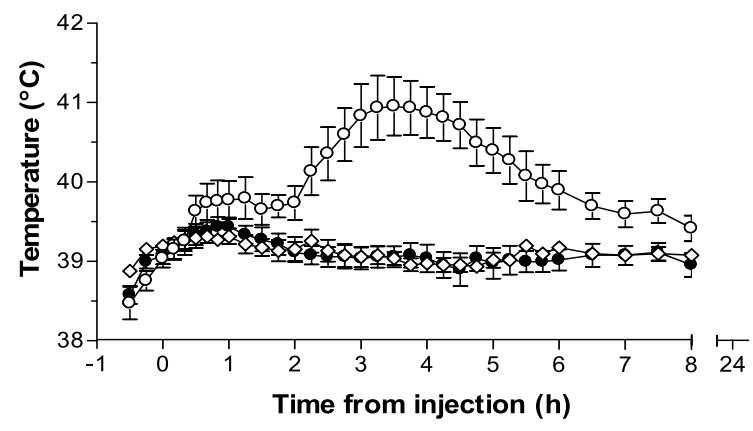

B

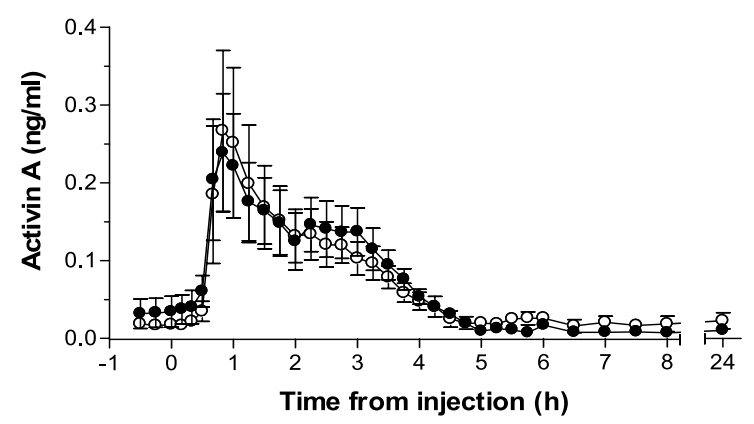

C

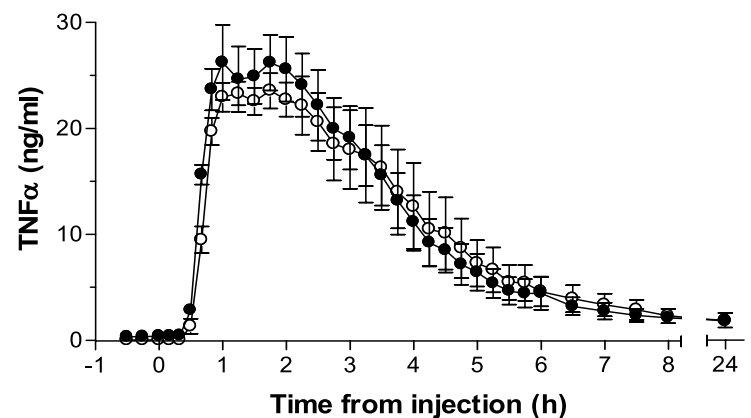

D

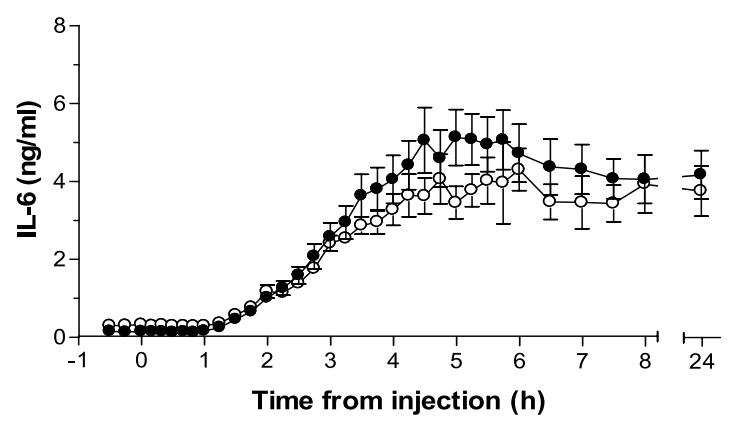

E

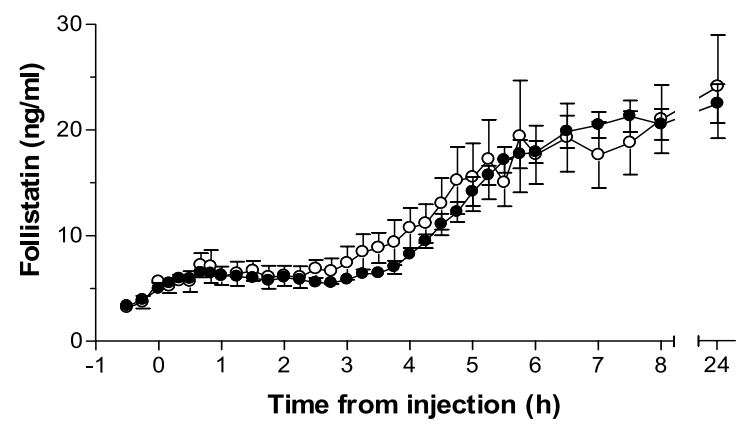

F

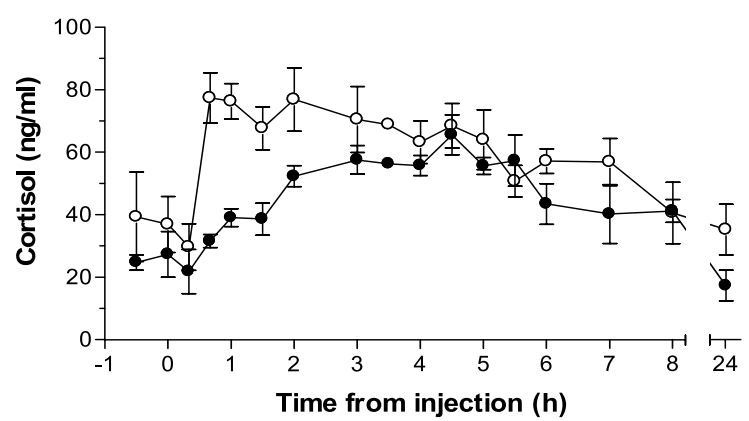

Figure 3 Profile changes of temperature and cytokines are represented over a $24 \mathrm{~h}$ period following challenge of adult ewes with $50 \mu \mathrm{g}$ LPS and blockade with the prostaglandin synthase antagonist, flurbiprofen. (A) Temperature changes of adult ewes to LPS (O), LPS and flurbiprofen $(\bullet)$ and non-pyrogenic saline $(\diamond,(A)$ only). Changes in plasma concentrations of $(B)$ activin A, (C) TNF $\alpha,(D)$ IL-6, (E) follistatin and $(\mathrm{F})$ cortisol. Values are means \pm S.E.M. $(n=5)$.

although blockade of IL-1 alone had no effect on IL-6 release, the effect of combined blockade of IL-1 and TNF $\alpha$ appeared synergistic as the IL-1RA had virtually no effect alone. The release of IL-6 was suppressed by more than $50 \%$, whereby IL-6 levels were significantly suppressed between 2 and $8 \mathrm{~h}$ following LPS $(P<0 \cdot 01$; Fig. $4 \mathrm{E}$ and Fig. 5E).

\section{Discussion}

This study significantly expands earlier observations that activin $\mathrm{A}$ is released into the bloodstream as an early event in the body's response to acute inflammatory challenge (Jones et al. 2000). The present studies also demonstrate that the release of activin A does not involve prostaglandins 
A

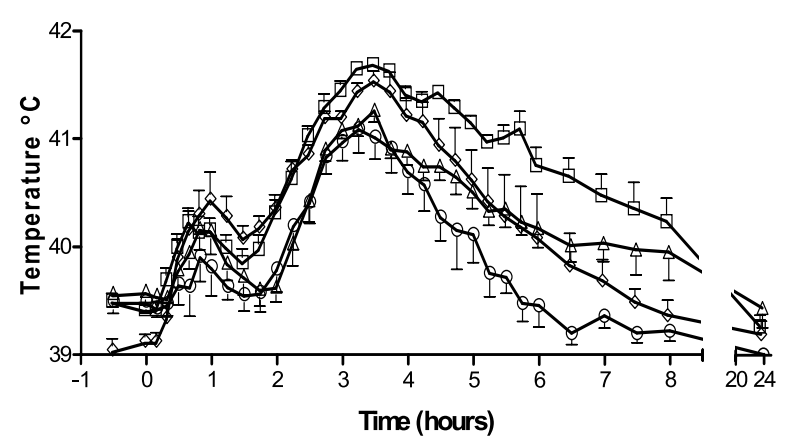

$\mathrm{C}$

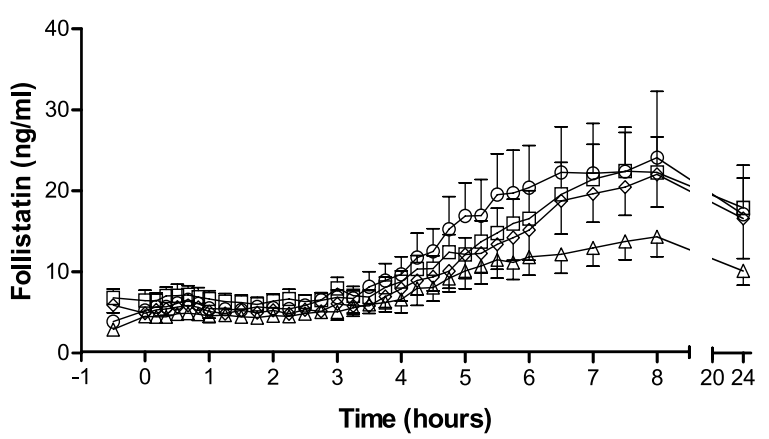

$\mathrm{E}$

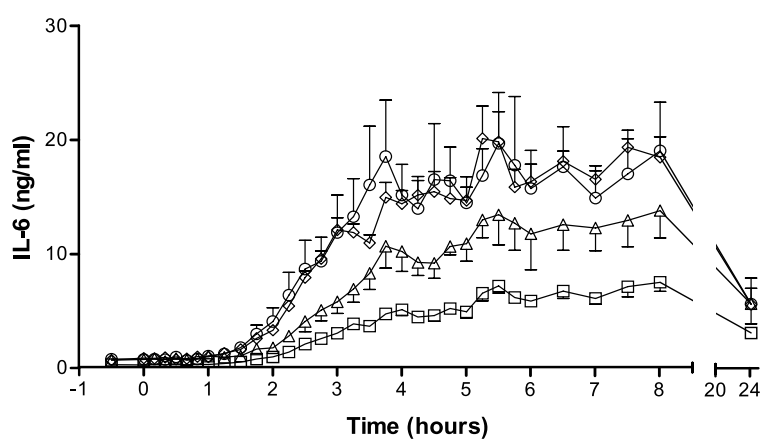

$\mathrm{B}$

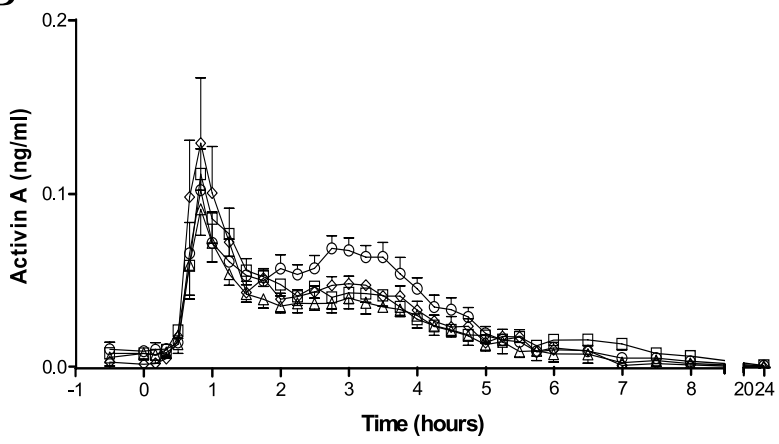

$\mathrm{D}$

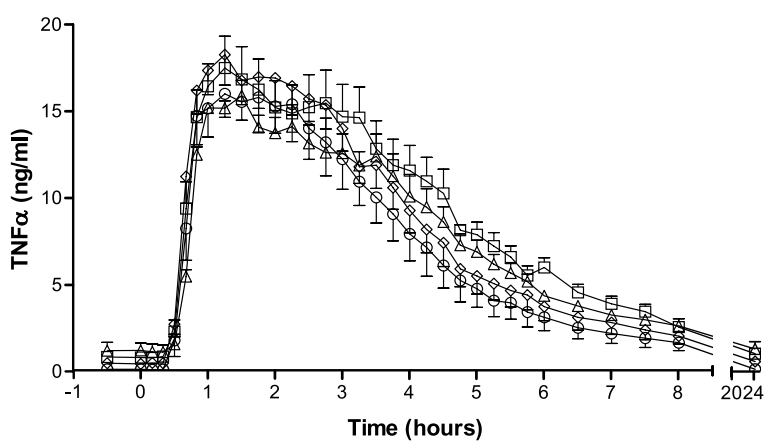

Figure 4 Changes in temperature and cytokine release are represented over a $24 \mathrm{~h}$ period following challenge with $50 \mu \mathrm{g}$ LPS $(O)$ and blockade with the cytokine antagonists, sTNF $\alpha$ R $(\triangle)$ or IL-1RA $(\diamond)$ or sTNF $\alpha$ R and IL-1RA $(\square)$. Profile changes are shown for temperature (A), activin A (B), follistatin (C), TNF $\alpha$ (D) and IL-6 (E). Values are means \pm S.E.M. $(n=5)$.

or IL-1 and that at least the initial release of activin A is not dependent on TNF $\alpha$ release. Further, activin A release appears to be independent of the centrally mounted fever response despite an apparently close temporal association. While the purpose of such a profound burst of activin A release remains to be resolved, it seems reasonable to propose that, as for TNF $\alpha$, this factor is an early 'alarm' response in the coordinated sequence of events that together form part of a defence system to combat infection at the local, tissue and systemic levels in the host.
In a previous study (Jones et al. 2000), it was reported that levels of plasma activin A were elevated within $1 \mathrm{~h}$ of LPS challenge. In the present study, the selection of more appropriate sampling timepoints allowed the release profile to be defined more rigorously. Using statistical criteria, activin A was first elevated 50 min after LPS and coincident with temperature, preceded the first elevation of $\mathrm{TNF} \alpha$, and peaked distinctly earlier than IL-6. In vitro studies with various cell types have shown that activin A mRNA expression and/or protein production can be 
A

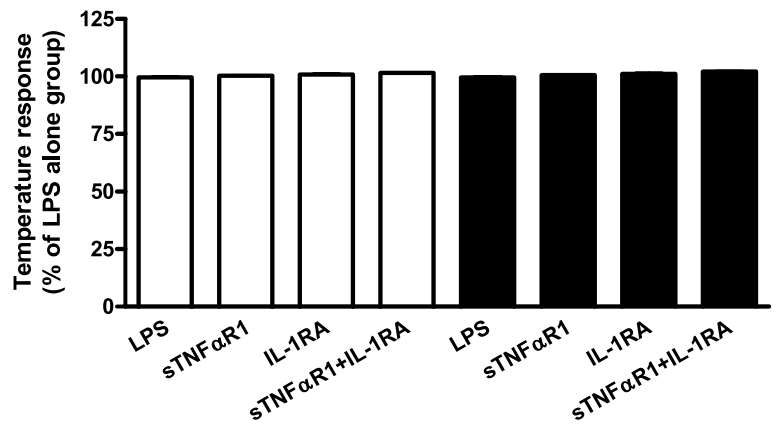

C

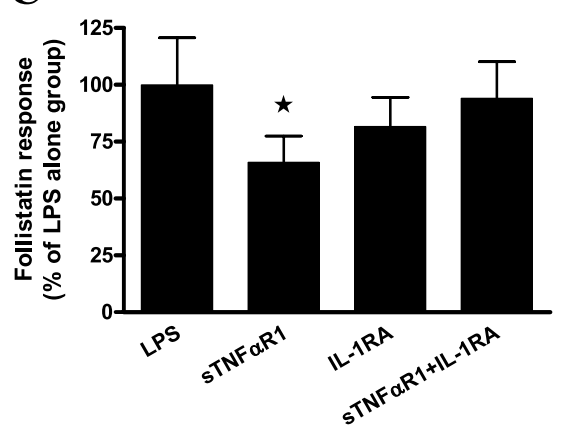

$\mathbf{E}$

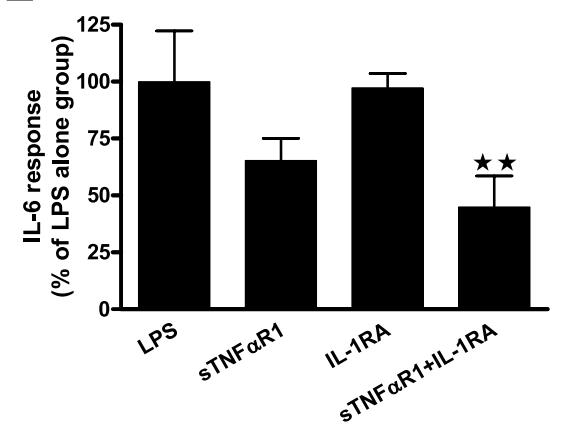

B

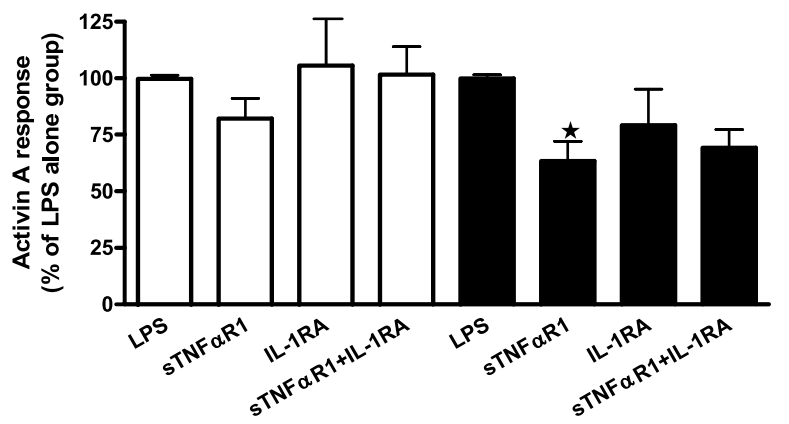

D

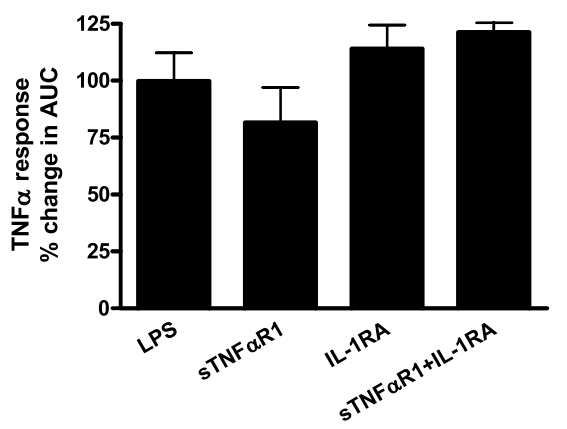

Figure 5 Cytokine responses, represented as the AUC relative to LPS stimulation alone, following treatment with soluble TNF $\alpha$ and/or IL-1 receptor antagonists. Groups of ewes $(n=5)$ were treated with LPS alone, LPS and sTNF $\alpha$ R, LPS and IL-1RA or LPS and both antagonists. Data are mean \pm S.E.M. ${ }^{*} P=0 \cdot 05 ;{ }^{*} P<0 \cdot 01$. For the temperature $(\mathrm{A})$ and activin $\mathrm{A}(\mathrm{B})$ responses, each phase of the biphasic response is depicted (Phase I open bars and Phase II filled bars), whereas for follistatin (C), TNF $\alpha$ (D) and IL-6 (E) is given. The actual response profiles are depicted in Fig. 4.

stimulated by pro-inflammatory cytokines such as TNF $\alpha$ and IL-1 $\beta$ (Shao et al. 1992, 1998). However, the present in vivo data indicate that when the bioactivity of TNF $\alpha$ and IL-1 was blocked using specific antagonists, the release of activin $\mathrm{A}$ in the initial peak was unchanged and was independent of the stimulatory effects of TNF $\alpha$ or IL-1. However, inhibition of TNF $\alpha$ bioactivity resulted in a diminution of the second phase of the activin response. These data raise the possibility that LPS, through its action on TLR4, may directly stimulate the release of activin A through specific NF- $\mathrm{KB}$ effects without the intermediary action of other cytokines. While it is possible that the amounts of the receptor antagonists employed were not sufficient to completely block TNF $\alpha$ and/or IL-1 action, these doses have been used previously to block LPSstimulated growth hormone release in sheep (Daniel et al. 2001).

The present results suggest that prostaglandins are not involved in the release of activin A following LPS, since blockade of prostaglandin synthesis by flurbiprofen did not alter the pattern of release but was effective in blocking the temperature rise. The response of activin A contrasts with the acute phase release of cortisol, oxytocin, growth hormone and GnRH (Massart-Leen \& Vandeputte-Van 
Messom 1991, Massart-Leen et al. 1992, Harris et al. 2000). These data also negate the possibility of a direct link between activin A and the fever response to LPS. This conclusion is further supported by the pilot study where activin A (1 or $5 \mu \mathrm{g})$ administered into the third ventricle did not induce any pyrogenic effect. It is likely that this lack of response observed in sheep was not due to the use of recombinant human activin A, as the protein is highly conserved between species, with one amino acid difference between human, bovine, ovine, porcine and rat sequences. Furthermore, recombinant human activin A injected into rats was demonstrated to increase the concentrations of red blood cells and haemoglobin (Schwall et al. 1989).

Despite the strong increase in plasma levels, no change in CSF concentrations of activin A were detected following peripheral LPS challenge. This selectivity in response was similar to that of TNFa. In contrast, IL-6 showed both peripheral and CNS responses and, of the major proinflammatory cytokines, appears to be the only example that has this property (Coceani et al. 1993). It should be pointed out, however, that the CNS can respond to immune challenge by releasing activin $\mathrm{A}$, as shown by elevated CSF concentrations in a rabbit model of meningitis (Michel et al. 2003b) and in human subjects with meningitis (U Michel, S Ebert \& D J Phillips, unpublished observations). These data, taken together with the sheep studies, suggest activin A release is confined to the compartment in which LPS is present. Furthermore, these data support the hypothesis that cellular activin A release requires a direct interaction with LPS or immediate downstream mediators, as LPS is unable to cross the blood-brain barrier (Dascombe \& Milton 1979). LPS has been shown to induce release of activin A from fibroblasts and upregulate the transcription of activin $\beta A$ mRNA in vitro, indicating that it may directly stimulate activin $\mathrm{A}$ synthesis and secretion (Shao et al. 1992, 1998). Furthermore, as the initial peak of activin A release was unaffected, and only the second peak was suppressed by blockade of TNF $\alpha$, these data infer that the initial activin A release is stimulated directly downstream of LPS-TLR4 interactions, does not require $\mathrm{NF}-\mathrm{\kappa B}$ induction and precedes TNF $\alpha$ actions.

The release of activin A preceded the release of follistatin by a number of hours and would suggest that the activin $\mathrm{A}$ released is unbound and therefore bioactive. Intriguingly, it may suggest that activin $\mathrm{A}$ is stimulating the subsequent release of follistatin. In vitro studies have shown activin A is capable of stimulating the release of follistatin (Shintani et al. 1997, Russell et al. 1999) as a short-loop feedback mechanism to limit the actions of activin. Furthermore, LPS can stimulate the release of IL-1 and IL-6 directly (Phillips et al. 1996, Vasilescu et al. 1996), which in turn are capable of regulating the production of follistatin (Phillips et al. 1996, Russell et al. 1999), lending weight to a high level of complexity in the regulation of activin activity. Alternatively, the release of follistatin may be unrelated to that of activin and may represent a direct stimulation by LPS, IL-1 and IL-6, as shown by in vitro studies using vascular endothelial cells (Michel et al. 1996). However, the failure of IL-1RA to influence that pattern of follistatin release after LPS makes it more likely that this response is a direct result of activin A stimulation.

It is likely that activin A release is directly downstream of the TLR4-LPS signal and the likely source(s) of activin A release are cell types responsive to LPS, that is, cells expressing the components of a functional TLR 4 receptor complex. This includes immune-responsive cells, such as monocytes, macrophages, neutrophils and also vascular endothelial cells (Shimazu et al. 1999). In vitro experiments have shown induction of activin $\beta_{\mathrm{A}}$ mRNA and protein in response to LPS and pro-inflammatory cytokines in monocytes and macrophages (Shao et al. 1992). Further, we have noted significant localisation of activin $\mathrm{A}$ in infiltrating macrophages in a rabbit model of meningitis (Michel et al. 2003b). A recent study showed that activin A release from monocytes and bone marrow stromal fibroblasts was markedly enhanced by the cognate interaction with T-cells in conjunction with cytokine stimulation, suggesting a complex level of interaction in activin A release from these cells (Abe et al. 2002). Neutrophils are also a key component in the initial response to innate host defence (Gregory \& Wing 2002), with a role for neutrophils suggested from immunohistochemical studies of human endometrium, where strong neutrophil staining for activin $\beta_{\mathrm{A}}$ subunit was present (Leung et al. 1998). We and others have also implicated vascular endothelial cells as a potential source of both activin A and follistatin following LPS challenge, but currently these studies are confined to in vitro observations (Michel et al. 1996, Brauman et al. 2000).

The important elements highlighted by this study are that activin A release following stimulation by LPS is likely to be biphasic, it is released rapidly suggesting that at least the initial component is pre-stored, and, most importantly, activin A release precedes that of follistatin suggesting that activin A would be bioavailable. In the broader context, the functional significance of these findings remains elusive due to the difficulty in generating models where the activin release is blocked by pharmacological means (such as concurrent administration of follistatin) or through transgenic approaches (for example, the perinatal lethality of the activin $\beta_{\mathrm{A}}$ knockout mouse (Matzuk et al. 1995)). Nevertheless, in vitro approaches suggest that activin A can have both pro- and anti-inflammatory actions depending on both cellular and temporal contexts (Phillips et al. 2001). For instance, activin A stimulates the production of pro-inflammatory cytokines, prostanoids and nitric oxide synthase in activated macrophages (Nüsing \& Barsig 1999), yet in other contexts it can antagonise the signalling of pro-inflammatory cytokines IL-1 $\beta$ and IL-6 (Brosh 
et al. 1995, Ohguchi et al. 1998). Furthermore, these studies suggest activin A release may require a direct interaction between LPS and its receptor, which is currently under investigation.

The duality of activin activity is consistent with the well-documented inflammatory actions of TGF $\beta$, which is structurally related to activin A and shares the intracellular Smad signalling system. Intriguingly, targeted disruption of Smad3, common to both activin and TGF $\beta$, results in impaired inflammatory responses (Ashcroft et al. 1999, Yang et al. 1999). Of particular interest will be to differentiate the effects of activin-mediated vs TGF $\beta$ mediated effects on inflammatory processes. Furthermore, of particular importance will be to determine the precise events involved in the release of activin A following LPS binding its receptor and identifying the cell type(s) responsible for the initial rapid release.

\section{Acknowledgements}

We thank Bruce Doughton, Karen Perkins, Sue Hayward, Anne O'Connor and Jan Loose for excellent technical assistance.

\section{Funding}

Amgen kindly providing both the sTNFaR and the IL-1RA; and the NHPP providing human recombinant activin A. This work was funded by the NHMRC of Australia (Program Grant 143786).

\section{References}

Abe M, Shintani Y, Eto Y, Harada K, Kosaka M \& Matsumoto T 2002 Potent induction of activin A secretion from monocytes and bone marrow stromal fibroblasts by cognate interaction with activated T cells. Journal of Lenkocyte Biology 72 347-352.

Ashcroft GS, Yang X, Glick AB, Weinstein M, Letterio JJ, Mizel DE, Anzano M, Greenwell-Wild T, Wahl SM, Deng C et al. 1999 Mice lacking Smad3 show accelerated wound healing and an impaired local inflammatory response. Nature Cell Biology 1 260-266.

Barker-Gibb ML, Scott CJ, Boublik JH \& Clarke IJ 1995 The role of neuropeptide Y (NPY) in the control of LH secretion in the ewe with respect to season, NPY receptor subtype and the site of action in the hypothalamus. Journal of Endocrinology 147 565-579.

Bocking AD, McMillen IC, Harding R \& Thorburn GD 1986 Effect of reduced uterine blood flow on fetal and maternal cortisol. Journal of Developmental Physiology 8 237-245.

Brauman JN, Smith AI, Scheerlinck J-PY, de Kretser DM \& Phillips DJ 2000 Activin A and follistatin responses to inflammatory mediators in the endothelium. Proceedings of the 11th International Congress of Endocrinology, Sydney, Australia. Abstract P512.

Brosh N, Sternberg D, Honigwachs-Sha'anani J, Lee B-C, Shav-Tal Y, Tzehoval E, Shulman LM, Toledo J, Hacham Y, Carmi P et al. 1995 The plasmacytoma growth inhibitor restrictin-P is an antagonist of interleukin 6 and interleukin 11. Identification as a stroma-derived activin A. Journal of Biological Chemistry 270 29594-29600.

Coceani F, Lees J, Mancilla J, Belizario J \& Dinarello CA 1993 Interleukin-6 and tumor necrosis factor in cerebrospinal fluid: changes during pyrogen fever. Brain Research 612 165-171.

Daniel JA, Whitlock BK, Steele B, Buxton DF \& Sartin JL 2001 Peripheral administration of interleukin-1 receptor antagonist or soluble tumor necrosis factor receptor blocks endotoxin induced growth hormone secretion. Proceedings of the 83rd Annual Meeting of The Endocrine Society, Denver, CO, USA. Abstract P2-597.

Dascombe MJ \& Milton AS 1979 Study on the possible entry of bacterial endotoxin and prostaglandin $\mathrm{E}_{2}$ into the central nervous system from the blood. British Journal of Pharmacology 66 565-572.

Ek M, Engblom D, Saha S, Blomqvist A, Jakobsson P-J \& Ericsson-Dahlstrand A 2001 Pathway across the blood-brain barrier. Nature 410 430-431.

Granowitz EV, Porat R, Mier JW, Pribble JP, Stiles DM, Bloedow DC, Catalano MA, Wolff SM \& Dinarello CA 1992

Pharmacokinetics, safety and immunomodulatory effects of human recombinant interleukin-1 receptor antagonist in healthy humans. Cytokine 4 353-360.

Gregory SH \& Wing EJ 2002 Neutrophil-Kupffer cell interaction: a critical component of host defenses to systemic bacterial infections. Journal of Leukocyte Biology 72 239-248.

Hanada T \& Yoshimura A 2002 Regulation of cytokine signaling and inflammation. Cytokine and Growth Factor Reviews 13 413-421.

Harris TG, Battaglia DF, Brown ME, Brown MB, Carlson NE, Viguié C, Williams CY \& Karsch FJ 2000 Prostaglandins mediate the endotoxin-induced suppression of pulsatile gonadotropinreleasing hormone and luteinizing hormone secretion in the ewe. Endocrinology 141 1050-1058.

Hübner G, Hu Q, Smola H \& Werner S 1996 Strong induction of activin expression after injury suggests an important role of activin in wound repair. Developmental Biology 173 490-498.

Hübner G, Brauchle M, Gregor M \& Werner S 1997 Activin A: a novel player and inflammatory marker in inflammatory bowel disease? Laboratory Investigation 77 311-318.

Jones KL, Brauman JN, Groome NP, de Kretser DM \& Phillips DJ 2000 Activin A release into the circulation is an early event in systemic inflammation and precedes the release of follistatin. Endocrinology 141 1905-1908.

Klein R, Robertson DM, Shukovski L, Findlay JK \& de Kretser DM 1991 The radioimmunoassay of follicle-stimulating hormone (FSH)-suppressing protein (FSP): stimulation of bovine granulosa cell FSP secretion by FSH. Endocrinology 128 1048-1056.

Klir JJ, Roth J, Szelényi Z, McClellan JL \& Kluger MJ 1993 Role of hypothalamic interleukin- 6 and tumor necrosis factor- $\alpha$ in LPS fever in rat. American Journal of Physiology 265 R512-R517.

Kluger MJ 1991 Fever: role of pyrogens and cryogens. Physiological Reviews 71 93-127.

Knight PG, Muttukrishna S \& Groome NP 1996 Development and application of a two-site enzyme immunoassay for the determination of 'total' activin-A concentrations in serum and follicular fluid. Journal of Endocrinology 148 267-279.

Leung PHY, Salamonsen LA \& Findlay JK 1998 Immunolocalization of inhibin and activin subunits in human endometrium across the menstrual cycle. Human Reproduction 13 3469-3477.

Massart-Leen AM \& Vandeputte-Van Messom G 1991 Role of prostaglandin-mediated mechanisms during experimentally induced endotoxin fever in the lactating goat. Koninklijke Vlaamse Academie Voor Geneeskunde Van Belgie 53 241-279.

Massart-Leen AM, Burvenich C, Vandeputte-Van Messom G \& Hilderson H 1992 Partial prostaglandin-mediated mechanism controlling the release of cortisol in plasma after intravenous administration of endotoxins. Domestic Animal Endocrinology 9 273-283. 
Matzuk MM, Kumar TR, Vassalli A, Bickenbach JR, Roop DR, Jaenisch R \& Bradley A 1995 Functional analysis of activins during mammalian development. Nature 374 354-356.

Michel U, Schneider O, Kirchhof C, Meisel S, Smirnov A, Wiltfang J \& Rieckmann P 1996 Production of follistatin in porcine endothelial cells: differential regulation by bacterial compounds and the synthetic glucocorticoid RU 28362. Endocrinology 137 4925-4934.

Michel U, Ebert S, Schneider O, Shintani Y, Bunkowski S, Smirnov A, Stringaris AK, Gerber J, Brück W \& Nau R 2000 Follistatin (FS) in human cerebrospinal fluid and regulation of FS expression in a mouse model of meningitis. European Journal of Endocrinology 143 809-816.

Michel U, Ebert S, Phillips D \& Nau R 2003a Serum concentrations of activin and follistatin are elevated and run in parallel in patients with septicemia. European Journal of Endocrinology 148 559-564.

Michel U, Gerber J, O'Connor AE, Bunkowski S, Brück W, Nau R \& Phillips DJ $2003 b$ Increased activin levels in cerebrospinal fluid of rabbits with bacterial meningitis are associated with activation of microglia. Journal of Neurochemistry 86 238-245.

Nüsing RM \& Barsig J 1999 Induction of prostanoid, nitric oxide, and cytokine formation in rat bone marrow derived macrophages by activin A. British Journal of Pharmacology 127 919-926.

Ohguchi M, Yamato K, Ishihara Y, Koide M, Ueda N, Okahashi N, Noguchi T, Kizaki M, Ikeda Y, Sugino H et al. 1998 Activin A regulates the production of mature interleukin- $1 \beta$ and interleukin-1 receptor antagonist in human monocytic cells. Journal of Interferon and Cytokine Research 18 491-498.

Phillips DJ 2001 New developments in the biology of inhibins, activins and follistatins. Trends in Endocrinology and Metabolism 12 94-96.

Phillips DJ 2003 The activin/inhibin family. In The Cytokine Handbook, edn 4, vol 2, pp 1153-1177. Eds A Thomson \& T Lotze. London: Elsevier Science Ltd.

Phillips DJ, Hedger MP, McFarlane JR, Klein R, Clarke IJ, Tilbrook AJ, Nash AD \& de Kretser DM 1996 Follistatin concentrations in male sheep increase following sham castration/castration or injection of interleukin-1 $\beta$. Journal of Endocrinology 151 119-124.

Phillips DJ, Jones KL, Scheerlinck J-PY, Hedger MP \& de Kretser DM 2001 Evidence for activin A and follistatin involvement in the systemic inflammatory response. Molecular and Cellular Endocrinology $180155-162$.

Robertson DM, Klein R, de Vos FL, McLachlan RI, Wettenhall REH, Hearn MTW, Burger HG \& de Kretser DM 1987 The isolation of polypeptides with FSH suppressing activity from bovine follicular fluid which are structurally different to inhibin. Biochemical and Biophysical Research Communications 149 744-749.
Rosenberg JJ, Martin SW, Seely JE, Kinstler O, Gaines GC, Fukuzuka K, Rose J, Kohno T, Boyle WJ, Nelson A et al. 2001 Development of a novel, nonimmunogenic, soluble human TNF receptor type I (sTNFR-I) construct in the baboon. Journal of Applied Physiology 91 2213-2223.

Russell CE, Hedger MP, Brauman JN, de Kretser DM \& Phillips DJ 1999 Activin A regulates growth and acute phase proteins in the human liver cell line, HepG2. Molecular and Cellular Endocrinology 148 129-136.

Schwall R, Schmelzer CH, Matsuyama E \& Mason AJ 1989 Multiple actions of recombinant activin-A in vivo. Endocrinology 125 1420-1423.

Shao L-E, Frigon NL Jr, Sehy DW, Yu AL, Lofgren J, Schwall R \& $\mathrm{Yu}$ J 1992 Regulation of production of activin A in human marrow stromal cells and monocytes. Experimental Hematology 20 1235-1242.

Shao L-E, Frigon NL Jr, Yu A, Palyash J \& Yu J 1998 Contrasting effects of inflammatory cytokines and glucocorticoids on the production of activin A in human marrow stromal cells and their implications. Cytokine 10 227-235.

Shimazu R, Akashi S, Ogata H, Nagai Y, Fukudome K, Miyake K \& Kimoto M 1999 MD-2, a molecule that confers lipopolysaccharide responsiveness on Toll-like receptor 4. Journal of Experimental Medicine 189 1777-1782.

Shintani Y, Dyson M, Drummond AE \& Findlay JK 1997 Regulation of follistatin production by rat granulosa cells in vitro. Endocrinology 138 2544-2551.

Ushikubi F, Segi E, Sugimoto Y, Murata T, Matsuoka T, Kobayashi T, Hizaki H, Tuboi K, Katsuyama M, Ichikawa A et al. 1998 Impaired febrile response in mice lacking the prostaglandin E receptor subtype $\mathrm{EP}_{3}$. Nature 395 281-284.

Vasilescu C, Berger D, Buttenschon K, Seidelmann M \& Beger HG 1996 Endotoxin-induced release of interleukin 6 and interleukin 1 beta in human blood is independent of tumor necrosis factor alpha. European Surgical Research 28 55-62.

Yang X, Letterio JJ, Lechleider RJ, Chen L, Hayman R, Gu H, Roberts AB \& Deng C 1999 Targeted disruption of SMAD3 results in impaired mucosal immunity and diminished $\mathrm{T}$ cell responsiveness to TGF- $\beta$. EMBO Journal 18 1280-1291.

Yu J \& Dolter KE 1997 Production of activin A and its roles in inflammation and hematopoiesis. Cytokines, Cellular and Molecular Therapy 3 169-177.

Received in final form 6 April 2004

Accepted 8 April 2004 